\title{
Accelerated weathering of PP based nanocomposites: Effect of the presence of maleic anhydryde grafted polypropylene
}

\author{
M. Morreale ${ }^{1}$, N. Tz. Dintcheva ${ }^{2 *}$, F. P. La Mantia ${ }^{2}$ \\ ${ }^{1}$ Università degli Studi di Enna „Kore”, Facoltà di Ingegneria, Architettura e delle Scienze Motorie, Cittadella \\ Universitaria, 94100 Enna, Italy \\ ${ }^{2}$ Dipartimento di Ingegneria Civile, Ambientale, Aerospaziale, dei Materiali, Università di Palermo, Viale delle Scienze, \\ Ed. 6, 90128 Palermo, Italy
}

Received 8 March 2013; accepted in revised form 9 May 2013

\begin{abstract}
Polymer nanocomposites are currently a topic of great interest. The increasing importance they are gaining also in the standpoint of industrial applications, is giving concerns regarding their environmental stability and, in general, their behaviour in outdoor applications, under direct solar irradiation. Papers available in the literature have highlighted the different influences of different nanosized fillers, in particular clay-based nanofillers; however, few data are available regarding other nanosized fillers. Furthermore, the research on polymer nanocomposites has clearly pointed out that the use of compatibilizers is required to improve the mechanical performance and the dispersion of polar fillers inside apolar polymer matrices, especially when complex mechanisms such as intercalation and exfoliation, typical of clay-filled nanocomposites, are involved. In this work, the photo-oxidation behaviour of polypropylene/clay and polypropylene/calcium carbonate nanocomposites containing different amounts of maleic anhydride grafted polypropylene (PPgMA) and subjected to accelerated weathering, was investigated. The results showed significant differences between the two nanofillers and different degradation behaviours in presence of the compatibilizer. In particular, PPgMA modified the dispersion of the nanofillers but, on the other hand, higher amounts proved to lead to the formation of some heterogeneities. Furthermore, PPgMA proved to positively affect the photo-oxidation behaviour by decreasing the rate of formation of the degradation products.
\end{abstract}

Keywords: nanocomposites, weathering stability, morphology, mechanical properties, FT-IR spectroscopy

\section{Introduction}

The use of nanometric-scale sized fillers for the preparation of thermoplastic polymer composites is of topical interest in the academia, because of the significant improvements achievable in terms of technological properties, such as the elastic modulus, the tensile strength, the barrier properties, the flexural modulus [1-8]. These enhancements are promising and attracting also the interest from industrial world, in sight of several applications which could benefit from them. On the other hand, it is known [3] that polymer based nanocomposites have been struggling to conquer mainstream volume market shares, and this can be attributed to some weaknesses. One of these is represented by their environmental stability, especially when outdoor applications (i.e. furnishing, building, packaging, automotive) are concerned.

It is known from the literature that polymer/silicate nanocomposites can show significant effects due to photo-oxidation (in particular, higher photo-oxidation rates and thus reduction of the mechanical prop-

\footnotetext{
*Corresponding author, e-mail: nadka.dintcheva@unipa.it

(c) BME-PT
} 
erties, in comparison to the pristine polymer matrix). These phenomena have been reported for several kinds of polymer used and were mainly attributed to a reduction of the photo-oxidation induction time [9-17]. This, in turn, was attributed to several factors, such as the presence of iron ions catalyzing the photo-oxidation process $[9,10]$, the formation of catalytic acidic sites or radicals following the decomposition of the organo-modifier (involving both the alkyl chain and the ammonium ions) [10-12, 17].

As regards the nanocomposites containing nanosized calcium carbonate, it was found [18] that the photo-oxidation rate increases in comparison to the pristine polymer matrix, and it was proposed that this might be attributed to several causes (nucleation phenomena, catalytic effects, presence of impurities or light sensitizers). Morreale et al. [19] performed a direct comparison between the photo-oxidation behaviours of silicate-filled and calcium carbonate-filled nanocomposites, finding that both organo-modified clay and nanometric calcium carbonate can increase the photo-oxidation rates; in particular, they showed how the nucleation phenomena, and thus the morphological and structural changes, can account for the photo-oxidation behaviour of calcium carbonate nanocomposites, and also that the distribution of photo-oxidation products in these nanocomposites is significantly different from that typically findable in those filled with organomodified clay.

Literature reports also about the photo-oxidation behaviour of clay-filled nanocomposites in presence of compatibilizers such as maleated polyolefins. Qin et al. [12] reported that maleic anhydride grafted polypropylene does not significantly modify the rate of photo-oxidation; Mailhot et al. [13] found that this compatibilizer can actually introduce some photo-responsive groups, leading to an acceleration of the photo-oxidation of polypropylene when used in combination with organophilic montmorillonite. However, to our present knowledge, there are few or no data regarding the photooxidation behaviour of polyolefin/calcium carbonate nanocomposites when a maleated polyolefin is added.

In this work, therefore, we investigated the behaviour of polypropylene (PP)/calcium carbonate nanocomposites in presence of different amounts of polypropylene grafted with maleic anhydride, and compared it with that of PP/organomodified montmorillonite nanocomposites.

\section{Experimental}

\subsection{Materials}

The PP used in this work was a Moplen X30G grade produced by Basell (Italy); the main properties according to the Producer are: density $=0.9 \mathrm{~g} \cdot \mathrm{cm}^{-3}$, melt index $\approx 8 \mathrm{~g} \cdot(10 \mathrm{~min})^{-1}$ (at $230^{\circ} \mathrm{C}$ and $\left.21.6 \mathrm{~N}\right)$ and melting temperature $T_{\mathrm{m}} \approx 170^{\circ} \mathrm{C}$. It is also known from the literature [20] that this general purpose PP usually contains small amounts of phenolic primary antioxidants and phosphite secondary antioxidants. However, it is known from the Literature that they are able to protect against thermal-oxidation during the processing $[9,11,14,17]$, but they have only an indirect influence on the photo-oxidation behaviour (for instance, by interfering with the formation of double bonds), which could be seen only as far as the final conditions are concerned, while the mechanisms and paths are not altered; furthermore, all of the systems prepared and investigated here contain practically the same amount of antioxidants, therefore their presence does not influence the comparisons. The nanosized fillers were a precipitated calcium carbonate, supplied by Solvay (Belgium) under the commercial name of Socal ${ }^{\circledR} 31$ (in the following indicated as S31), with a calcite rhombohedral crystal structure, cube-like crystal shape and a mean particle diameter 50-100 nm [21], and a montmorillonite clay produced by Southern Clay Products (USA) and commercialized as Cloisite ${ }^{\circledR} 15 \mathrm{~A}$ (further indicated as CL15A; modified with dimethyldihydrogenated tallow-quaternary ammonium chloride quaternary surfactant; quaternary concentration $=12 \mathrm{meq} \cdot(100 \mathrm{~g})^{-1}$ clay; $d_{001}=3.15 \mathrm{~nm}$; density $=$ $\left.1.66 \mathrm{~g} \cdot \mathrm{cm}^{-3}\right)$.

The coupling agent was a polypropylene grafted with maleic anhydride (PPgMA), supplied by Sigma Aldrich (USA), with maleic anhydride content 8 $10 \mathrm{wt} \%$ and melting temperature $=156^{\circ} \mathrm{C}$.

The nanocomposite systems were prepared by always using a $5 \mathrm{wt} \%$ amount of the filler (clay or calcium carbonate), while the PP/PPgMA ratio changed from $100 / 0,95 / 5,85 / 15$ to $75 / 25$.

\subsection{Processing}

The neat PP, the binary PP/PPgMA blend and the nanocomposites were prepared in a co-rotating intermeshing twin-screw extruder (OMC, Italy), having $L / D=35, D=19 \mathrm{~mm}$. The adopted temperature profile was $120-130-140-150-160-170-190^{\circ} \mathrm{C}$ (die), with screw speed set at $200 \mathrm{rpm}$ and the speed of 
the gravimetric feeder set at $10 \mathrm{rpm}$. The extrudates were water cooled and granulated by means of an Accrapak (UK) rotating blade system. Specimens for mechanical, calorimetric, morphological and Fourier transform infrared (FTIR) spectral characterization were prepared by compression moulding, using a Carver (USA) laboratory press set at $190^{\circ} \mathrm{C}$ $(15 \mathrm{~cm} \times 15 \mathrm{~cm}$ electrically heated and water cooled plates, pressure about $20 \mathrm{MPa}$, compression time 3-4 min).

\subsection{Accelerated weathering}

The compression moulded sheets were subjected to accelerated weathering conditions in a Q-UV (QLab Corp., USA) apparatus, containing eight UVB313 lamps. The exposure cycle conditions were $8 \mathrm{~h}$ of light at a temperature of $55^{\circ} \mathrm{C}$ followed by $4 \mathrm{~h}$ condensation at $35^{\circ} \mathrm{C}$.

\subsection{Mechanical characterization}

Tensile properties (elastic modulus, tensile strength and elongation at break) were determined according to ASTM D882, with the help of an Instron mod. 3365 (USA) apparatus. The specimens were cut from the compression-moulded sheets and tested at $5 \mathrm{~mm} / \mathrm{min}$ crosshead speed. At least seven samples were tested for each tensile property and the average values (with the corresponding error bars) are reported. In the case of photo-oxidized samples, at least five samples were tested and the reproducibility was about $\pm 6 \%$.

\subsection{Differential scanning calorimetry}

Calorimetric data were obtained using a Perkin-Elmer DSC7 apparatus, at scanning rate of $10^{\circ} \mathrm{C} \cdot \mathrm{min}^{-1}$ in the temperature range from 30 to $210^{\circ} \mathrm{C}$. At least three samples for each formulation were tested and the reproducibility of the collected data was satisfactory $( \pm 4 \%)$.

\subsection{FTIR analysis}

A Fourier Transform Infrared (FTIR) spectrometer (Spectrum One, Perkin-Elmer, UK) was used to record FTIR spectra of the samples, performing 16 scans at a resolution of $1 \mathrm{~cm}^{-1}$ (in the range 450$4000 \mathrm{~cm}^{-1}$ ). The relative concentration of functional groups was determined from their peak absorption area index (absorbance peak area of the chemical group compared to that of the reference absorption peak area located at $2722 \mathrm{~cm}^{-1}$ and being known as the sum of the $\delta\left(\mathrm{CH}_{2}\right)$ and $\gamma_{\mathrm{t}}\left(\mathrm{CH}_{2}\right)$ vibrations [22]). Measurements were obtained from the average of three samples, with a calculated reproducibility of $\pm 3 \%$.

\subsection{Morphological characterization by SEM}

The scanning electron microscopic (SEM) analysis was performed by scanning of the nitrogen fractured surfaces of the specimens, using a FEI (USA) Quanta F200 equipment.

\subsection{X-ray analysis}

Wide angle X-ray diffraction (WAXD) patterns were obtained at room temperature by using a Siemens (Germany) D-500 X-ray diffractometer in the reflection mode with $\mathrm{Cu} \mathrm{K} \mathrm{K}_{\alpha}$ incident radiation of wavelength $0.1542 \mathrm{~nm}$.

The interlayer distance was calculated using Bragg's formula (Equation (1)):

$d_{001}=\frac{n \lambda}{2 \sin \theta}$

From the results, it was possible to calculate the number of clay platelets per average stack with the interlayer distance $d_{001}$ using Equation (2):

$N=1+\frac{t}{d_{001}}$

where $t$ is given by the Scherrer's formula, $t=$ $0.9 \lambda /\left(B_{1 / 2} \cdot \cos \theta_{\mathrm{b}}\right), \lambda$ is the wavelength, $B_{1 / 2}=\theta_{1}-\theta_{2}$ (in radiants) at half peak height $\left(I_{\max / 2}\right), \theta_{\mathrm{b}}=$ $\left(\theta_{1}+\theta_{2}\right) / 2$ [23].

\subsection{TEM analysis}

Tansmission electron microscopic (TEM) observations were made with a ZEISS (Germany) EM 900 microscope, at accelerating voltages of 50 and $80 \mathrm{KeV}$, in the Genoa division of the Institute for Macromolecular Studies (ISMac) of CNR (Italian National Research Council). The dimension of the microtomed sample was about $10 \mu \mathrm{m}$.

\section{Results and discussion}

Figure 1a-1c report respectively the tensile modulus, tensile strength and elongation at break for the investigated systems (unfilled polymer, composite with modified clay and composite with nanosized calcium carbonate) as a function of the PP-PPgMA ratio (from $100 / 0$ to $75 / 25$, as described in the experimental part). 

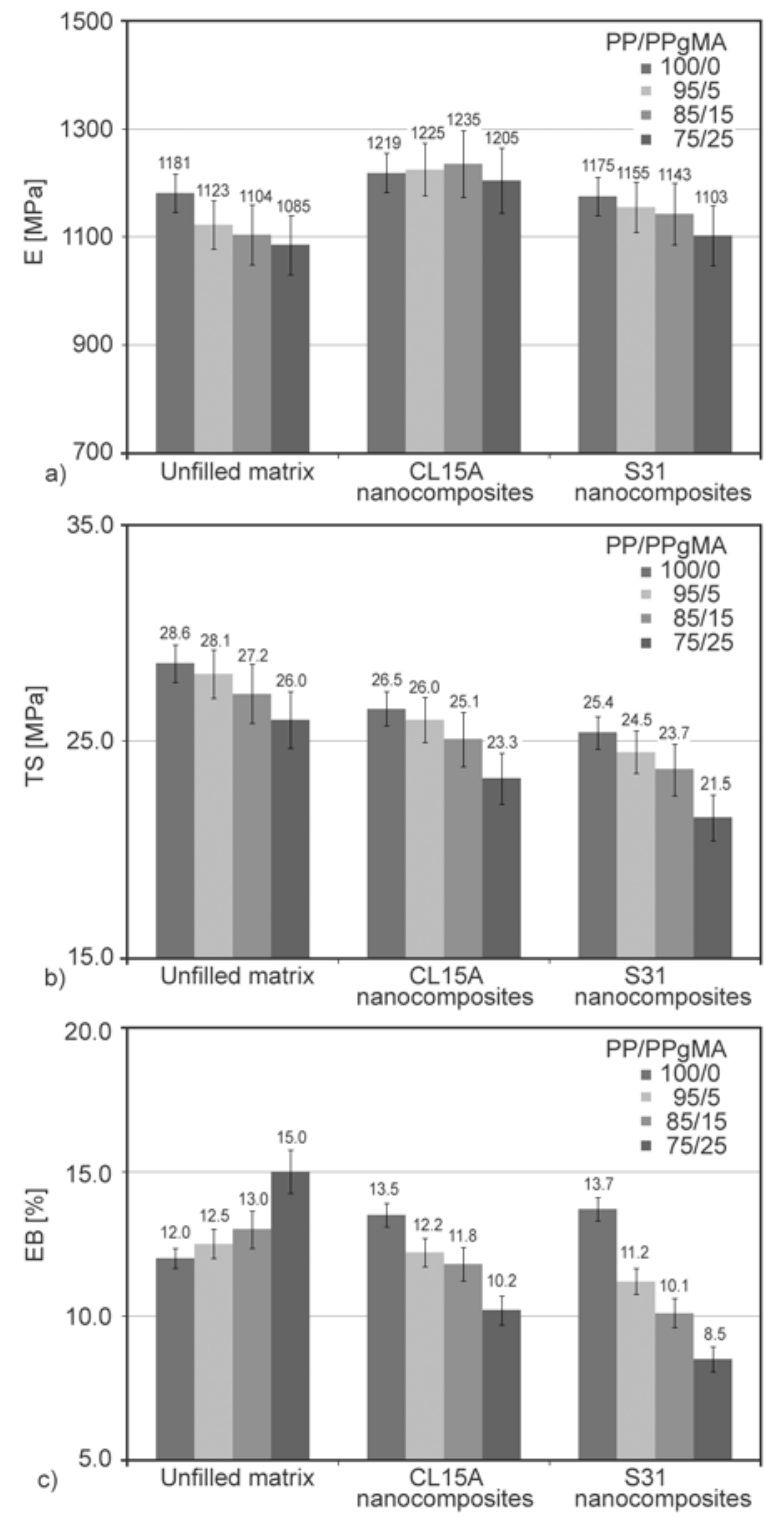

Figure 1. Main mechanical properties: (a) elastic modulus, $E$, (b) tensile strength, $T S$, (c) elongation at break, $E B$, of the unfilled matrix, CL15A nanocomposites and S31 nanocomposites with different PP/PPgMA ratios

As regards the elastic modulus, the addition of PPgMA leads to a significant reduction of the rigidity of the material (higher upon increasing the MA content), in agreement with previous results on similar systems [17]. The behavior is completely different as far as the nanocomposites are concerned: the elastic modulus keeps practically unchanged, and some reductions (however, not higher than 5\%) are experienced only in the S31-filled nanocomposite at higher PPgMA content. On the average, the nanocomposites keep higher moduli than the corresponding unfilled systems, and the CL15A filled ones show the highest overall values. Indeed, the overall results can be explained by taking into account two different factors: the presence of PPgMA and the effect of the filler. When PPgMA is added to the PP at sufficiently high amounts, the polymer matrix actually becomes a polymer blend. In polymer blends, the properties typically vary according to the values of the properties of the pure components, as well as their relative amounts [24]. Significant deviations from this behavior can be present mainly when synergistic or strong incompatibility issues occur [24, 25]. In the case of this study, PPgMA has lower elastic modulus (not reported here for sake of conciseness) than that of pure PP, therefore the blends have decreasing modulus (Figure 1a) upon increasing the PPgMA content. The same explanation holds for the tensile strength (Figure 1b) and the elongation at break (Figure 1c): in this last case, the value increases due to the higher ductility of PPgMA. However, as far as the nanocomposites are concerned, there is one more factor to be taken into account, i.e. the presence of the filler and the role of its interface with the matrix. In fact, the presence of PPgMA can improve the adhesion between the matrix and the filler, and this effect counterbalances the lower rigidity given by PPgMA. In summary, the mechanical properties trends of the nanocomposites can be explained by taking into account both the two factors, which can be in contrast and lead to opposite directions according to which of the two prevails.

With particular concern to the tensile strength, the presence of CL15A and S31 leads to small reductions of the resistance, in agreement with our previous results [19]. In general, it can be stated that both the breaking properties (tensile strength and elongation at break) are ruled by the heterogeneity of the system [24], which obviously increases upon increasing the amount of PPgMA and reaches a maximum at the 75/25 PP-to-PPgMA ratio. This helps to explain the nanocomposites behavior observable in Figure $1 \mathrm{~b}$ and $1 \mathrm{c}$, i.e. the reduction of tensile strength and elongation at break upon increasing the PPgMA content, and will be further discussed with reference to morphological analysis, below reported.

Figure 2a, 2b, show respectively the enthalpies of melting and crystallization for the investigated systems, obtained by DSC analysis. Both the melting and the crystallization enthalpy tend to decrease upon increasing the PPgMA content; it can be, on the whole, stated that the calorimetric data are in per- 

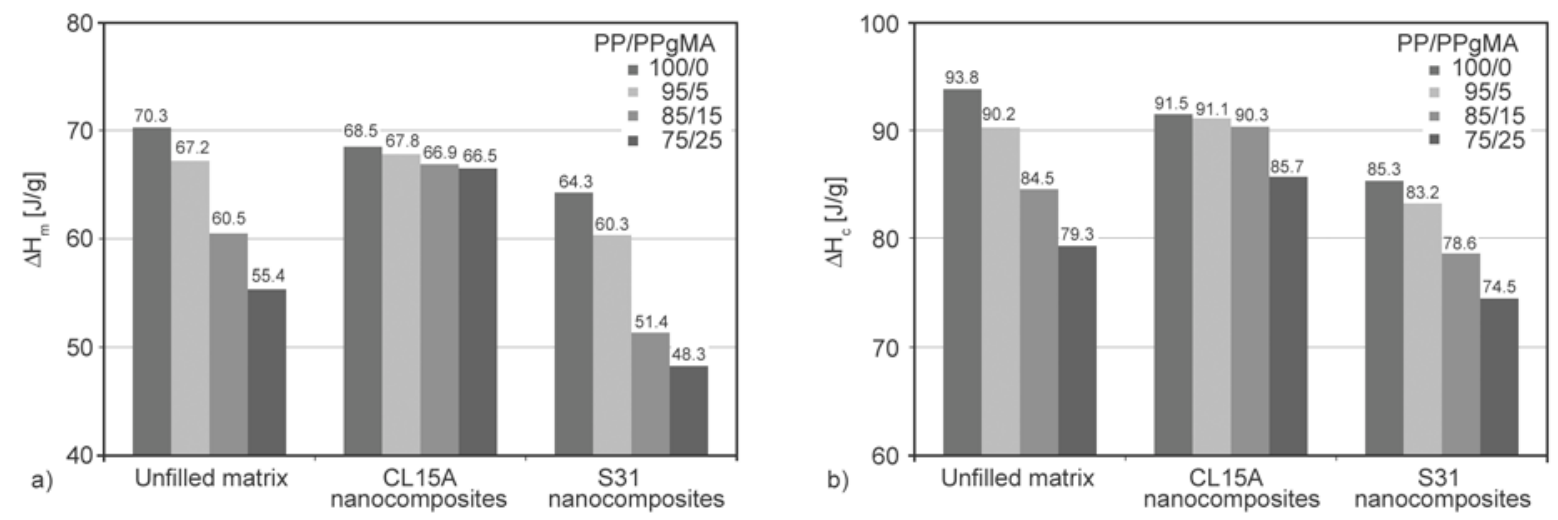

Figure 2. Enthalpies of (a) melting and (b) crystallization of the unfilled matrix, CL15A nanocomposites and S31 nanocomposites with different PP/PPgMA ratios

fect agreement with the values of the elastic modulus: the reduced crystallinity upon increasing the PPgMA content thus accounts for the reduction in the elastic modulus, which is counterbalanced, in the nanocomposites, by the presence of the filler and the compatibilizer.

Figure 3 reports the morphology of some representative samples, obtained by SEM and TEM analysis, as well as our graphic interpretation of the morphology. It can be observed that the SEM morphology of the fracture surface of the polymer (i.e. without filler) appears, in general, slightly more homogeneous upon adding PPgMA (see Figure 3a), while no significant differences are detectable between the SEM morphologies of CL15A nanocomposites without and with 75/25 PP/PPgMA ratio (Figure 3b). Important information is, on the other hand, obtainable from the TEM images reported in the same figure: the filler dispersion upon adding PPgMA is significantly improved. However, as previously mentioned with regard to the mechanical properties, although PP and PPgMA are physically miscible (thus forming a polymer blend without observable phase separation, as shown by the SEM images), they are not chemically compatible [26, 27]; therefore, higher PPgMA contents (as in the case of $75 / 25$ systems) are likely to form heterogeneous micro-zones as schematically shown in the drawings in Figure 3b, where a graphical interpretation of the system structure at nanometric scale is provided for CL15A nanocomposite (left) and CL15A nanocomposite with 75/25 PP/PPgMA ratio (right). The presence of PPgMA increases clay dispersion (with partial exfoliation, as further proved by XRD analysis which will be described in the following) and should therefore improve the mechanical prop- erties, but its high amount and its chemical incompatibility leads to the formation of heterogeneities (grey in the drawings) consisting in PPgMA with some clay particles at the inside. The considerations about selective disposition of the clay platelets and stakes, especially into the more polar phase, within the incompatible polymer blends, have been also made on the base of our previous studies [28, 29]. This can also help in explaining the reduction of the tensile strength and the elongation at break upon increasing the PPgMA content, as already pointed out in the discussion about the mechanical properties (Figures $1 \mathrm{~b}$ and $1 \mathrm{c}$ ), in spite of the improved filler dispersion. As regards the S31 nanocomposites with and without PPgMA, SEM images as well as our graphical interpretations of the inner morphology at nanometric scale are provided in Figure $3 \mathrm{c}$. The presence of PPgMA helps in improving the dispersion but, on the other hand, similar phenomena as in the case of CL15A nanocomposites can occur (grey zones). It was mentioned above that further information in the direction of clay behaviour in terms of dispersion and morphology was provided by XRD analysis; the results are reported in Table 1. The interlayer distance of the clay increases in the nanocomposite without PPgMA, showing that some intercalation occurs and confirming the result suggested by the TEM image (predominantly intercalated morphology). When PPgMA is added, the interlayer distance increases upon increasing the PPgMA content, to such a level that, when a 75/25 PP-to-PPgMA ratio is adopted, the results coming from XRD and TEM analyses prove that a mixed intercalated/exfoliated (predominantly exfoliated) morphology is achieved. Figure $4 \mathrm{a}$ and $4 \mathrm{~b}$ report, respectively, the dimensionless elastic modulus ( $E$ at time ' $t$ ' vs $E$ at time 

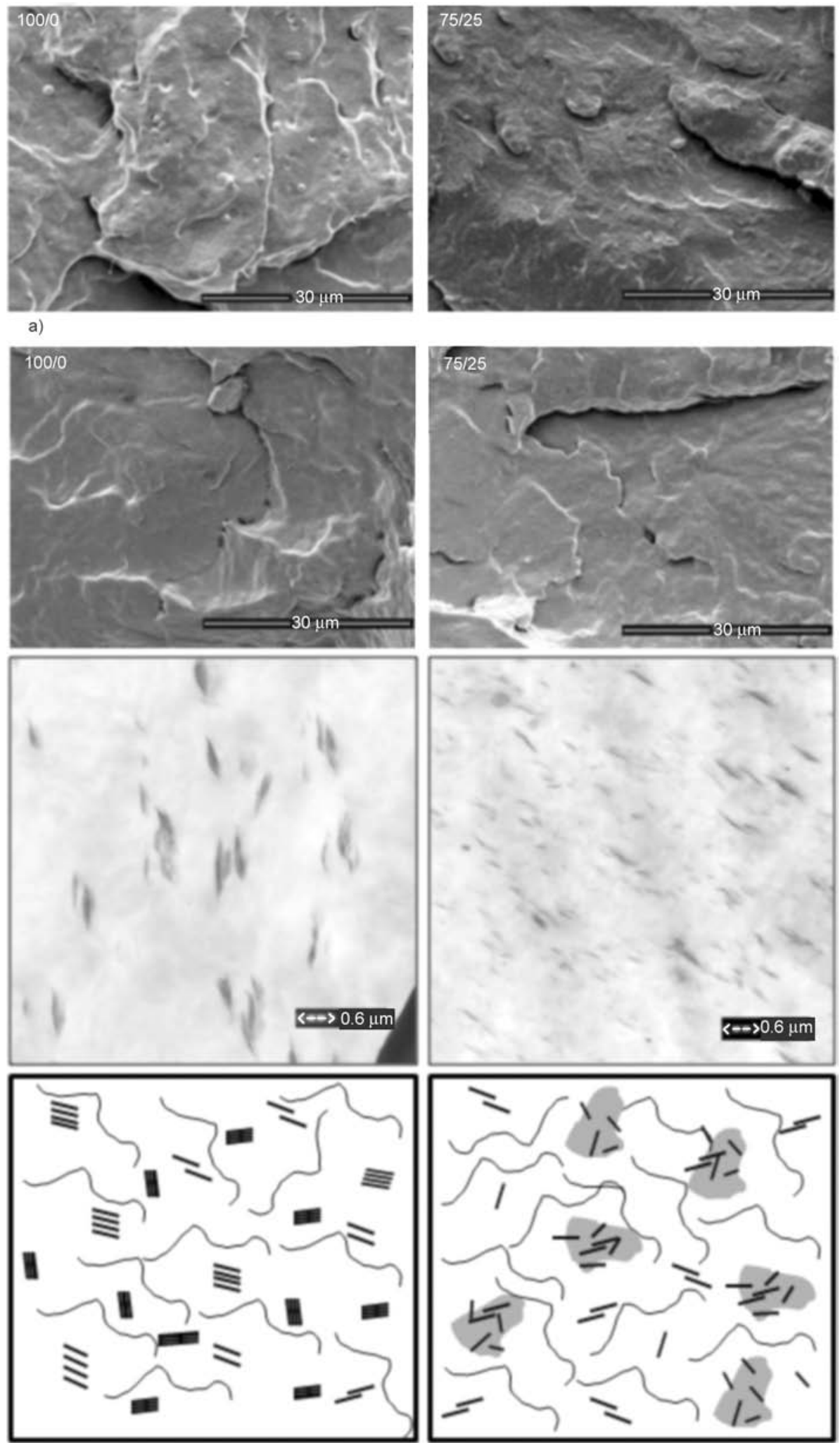

b)

Figure 3a, b. SEM, TEM images and graphic interpretation of some investigated samples: (a) PP/PPgMA = 100/0 and 75/25, (b) CL15A nanocomposite where PP/PPgMA = 100/0 and 75/25

zero) of the samples containing clay (a) or calcium carbonate (b), upon increasing the photo-oxidation time; the figures contain also the data of the PPPPgMA blends. The reported data clearly outline that an increase of the elastic modulus occurs upon increasing the accelerated weathering time, in agreement with our previous results and other studies on similar systems $[9,19]$. The presence of the nano- 

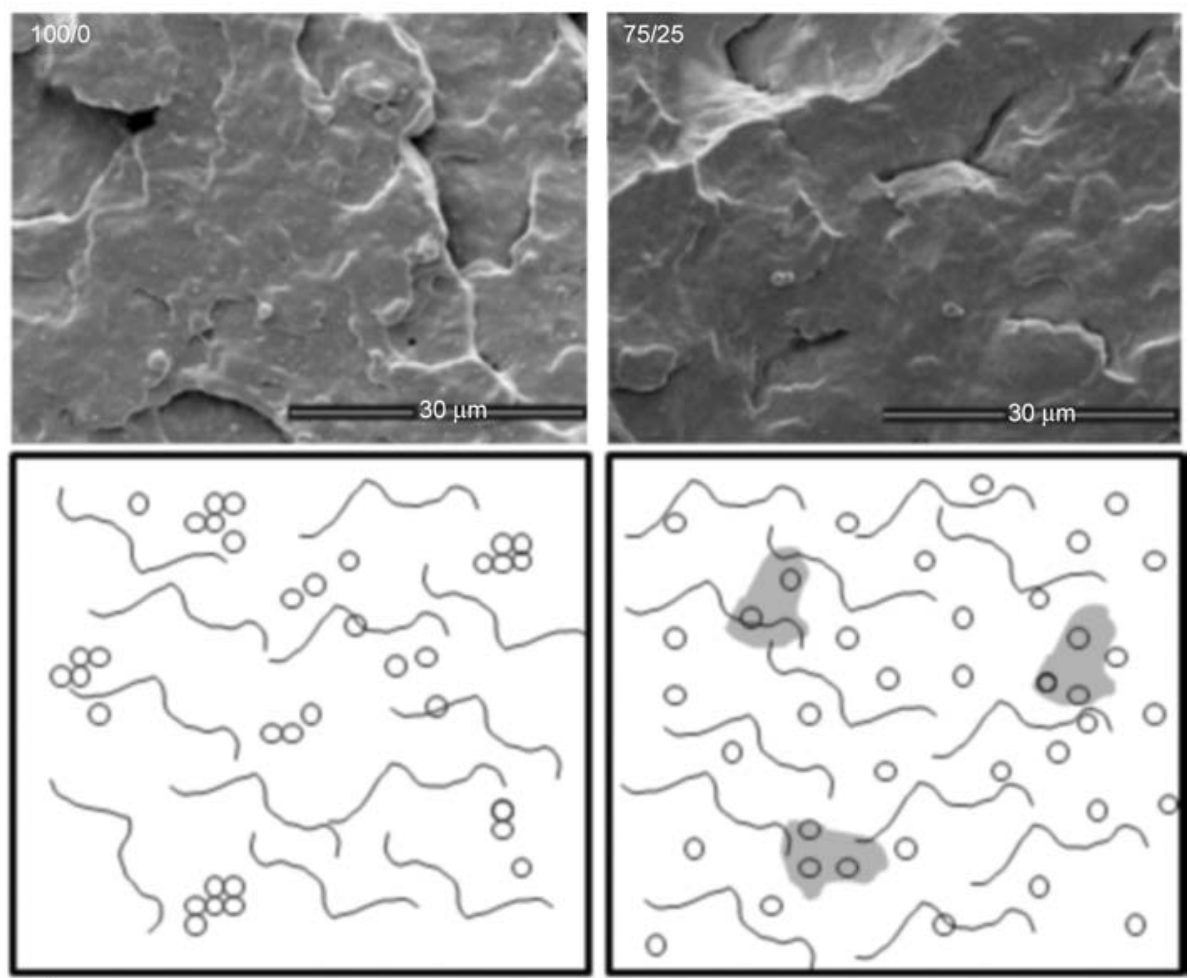

c)

Figure 3c. SEM, TEM images and graphic interpretation of some investigated samples: (c) S31 nanocomposite where $\mathrm{PP} / \mathrm{PPgMA}=100 / 0$ and $75 / 25$

Table 1. Main XRD peaks and interlayer distances for pristine clay and nanocomposite systems

\begin{tabular}{|c|c|c|c|}
\hline Sample & $\begin{array}{c}\text { Main peak } 2 \theta \\
{\left[{ }^{\circ}\right]}\end{array}$ & $\begin{array}{c}\text { Interlayer distance } d_{001} \\
{[\mathrm{~nm}]}\end{array}$ & $\begin{array}{c}\text { Platelets/stack } \\
{[\mathbf{N}]}\end{array}$ \\
\hline CL15A & 2.80 & 3.15 & 3.11 \\
\hline $\mathrm{PP} / \mathrm{PPgMA} / \mathrm{CL} 15 \mathrm{~A}=100 / 0 / 5$ & 2.67 & 3.30 & 2.61 \\
\hline PP/PPgMA/CL15A = 95/5/5 & 2.58 & 3.42 & 2.33 \\
\hline PP/PPgMA/CL15A $=85 / 15 / 5$ & 2.32 & 3.81 & 2.08 \\
\hline PP/PPgMA/CL15A $=75 / 25 / 5$ & 2.16 & 4.10 & 2.02 \\
\hline
\end{tabular}

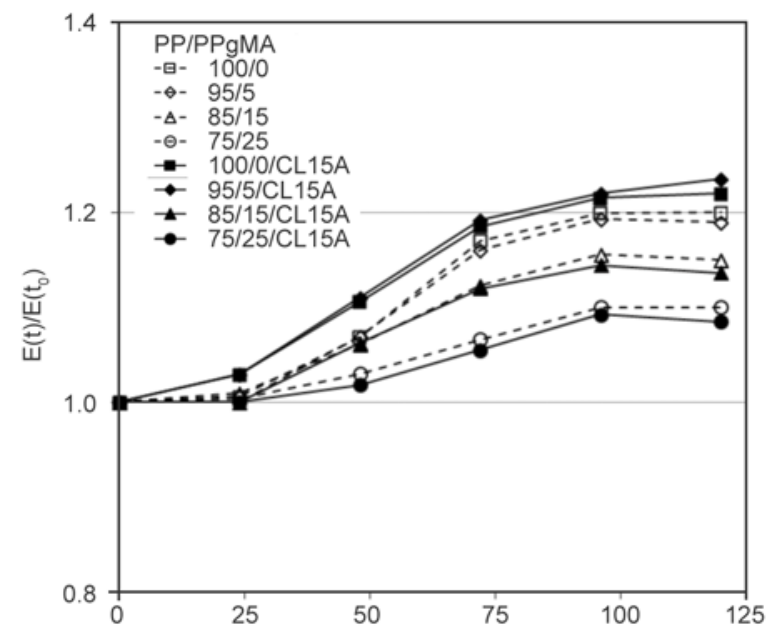

a)

Photo-oxidation time $[\mathrm{h}]$

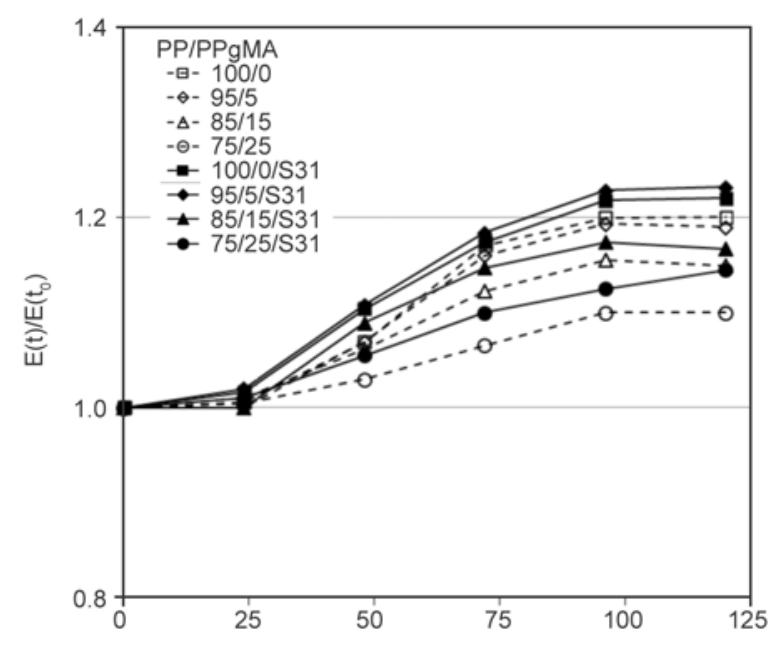

b)

Photo-oxidation time [h]

Figure 4. Dimensionless elastic modulus of samples at different PP/PPgMA ratios with (a) CL15A and (b) S31, as a function of the photo-oxidation times 

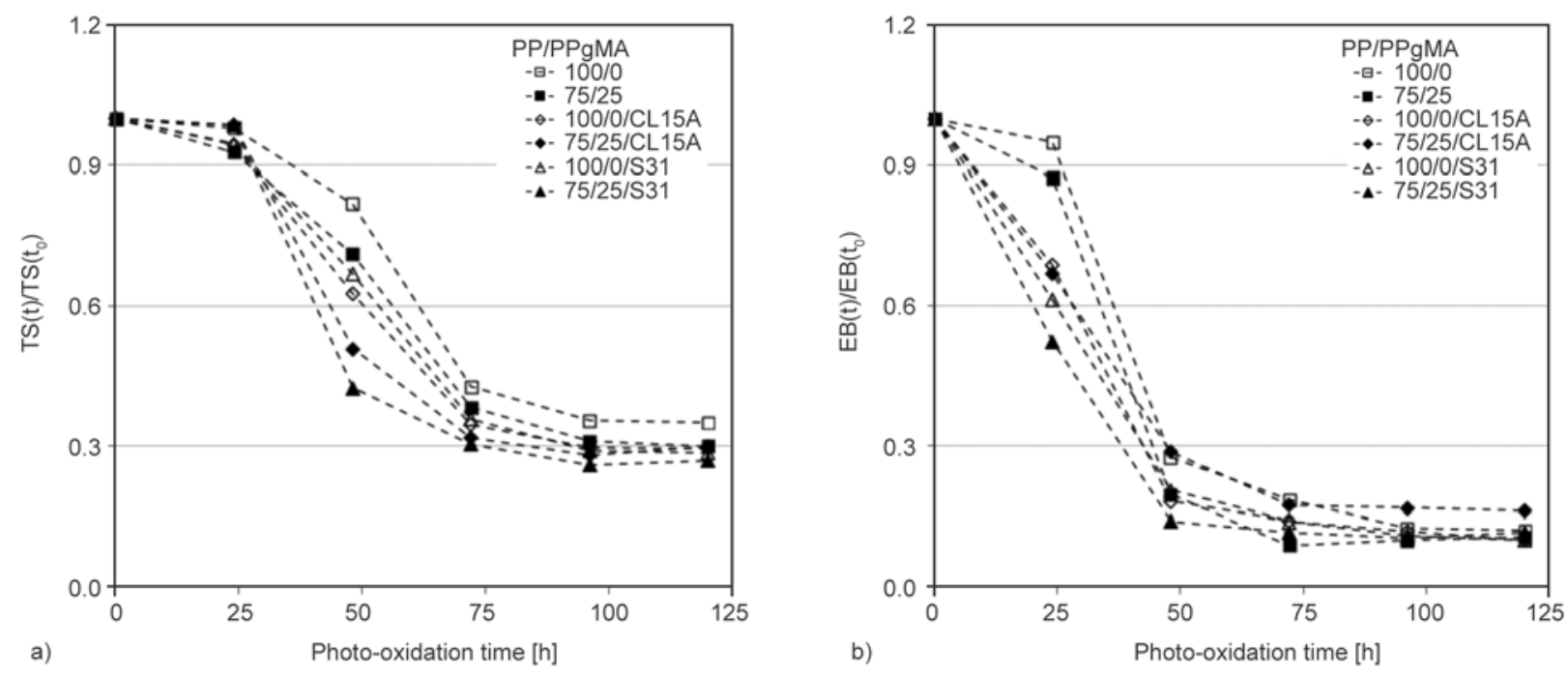

Figure 5. Dimensionless (a) tensile strength and (b) elongation at break of some investigated samples (at different PP/PPgMA ratios) as a function of the photo-oxidation times

sized fillers does not lead to significant differences in the increase of the elastic modulus, if compared to the unfilled binary blends. On the other hand, from all of the systems (binary blend, clay-filled nanocomposite and calcium carbonate filled nanocomposite) a clear tendency emerges, i.e. the decrease of the stiffening effect with time, when higher amounts of PPgMA are used; in other words, the presence of increasing amounts of PPgMA seems to lead to reduced photo-oxidation effects, although the differences are not striking.

The dimensionless tensile strength and elongation at break upon increasing the photo-oxidation time are reported in Figure 5a and 5b, respectively. The breaking properties experience a dramatic drop

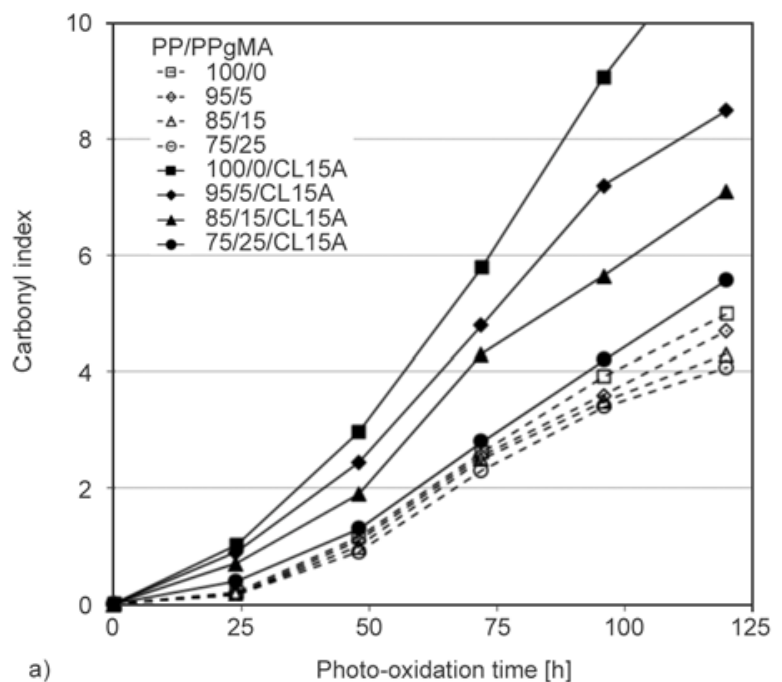

upon increasing the photo-oxidation time (especially after $48 \mathrm{~h}$ ), while the presence of PPgMA and the variation of its percentage do not significantly change the overall behavior: the difficulties in extrapolating variations in the systems with different PPgMA amount and/or filler type are due, once more, to the previously mentioned heterogeneity of the investigated systems.

Carbonyl index $(\mathrm{CI})$ is reported in Figure $6 \mathrm{a}$ and $6 \mathrm{~b}$, for CL15A and S31 filled nanocomposites, respectively, and compared with the unfilled binary blends. The diagrams show an expected increase of the CIs of all the investigated samples upon increasing the photo-oxidation time. However, a very clear trend emerges, which was already, at least partially, pres-

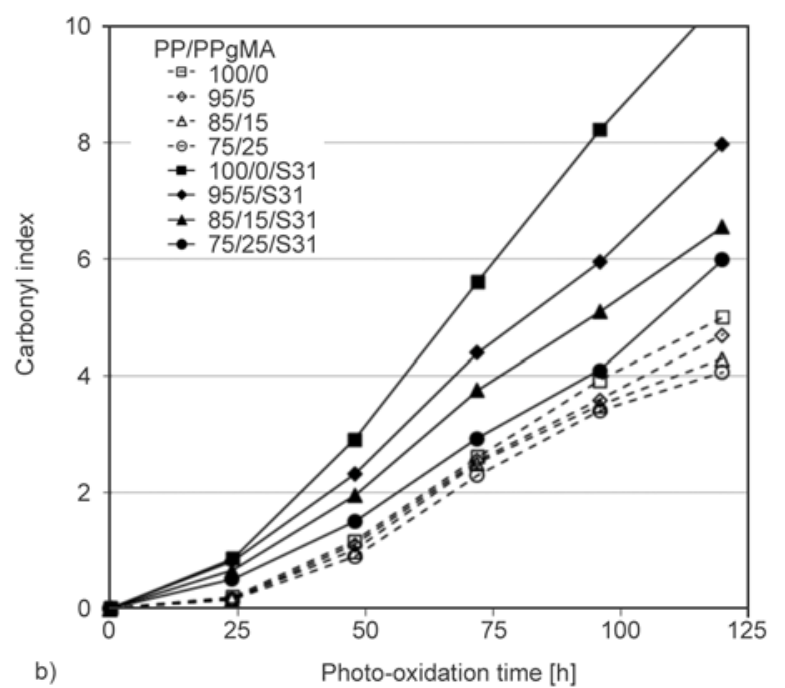

Figure 6. Carbonyl index of (a) CL15A and (b) S31 nanocomposites at different PP/PPgMA ratios, as a function the photooxidation times 
ent in the previous discussed experimental observations on the mechanical behavior: the increase of CI is lower upon increasing the PPgMA, both in the unfilled binary blends and in the nanocomposites. This suggests that the presence of PPgMA actually reduces the photo-oxidation products formation. This is particularly true in the nanocomposites where, after 120 hours, the CIs of the systems at 75/25 PPto-PPgMA ratios are approximately one half of those of the nanocomposites without PPgMA. This
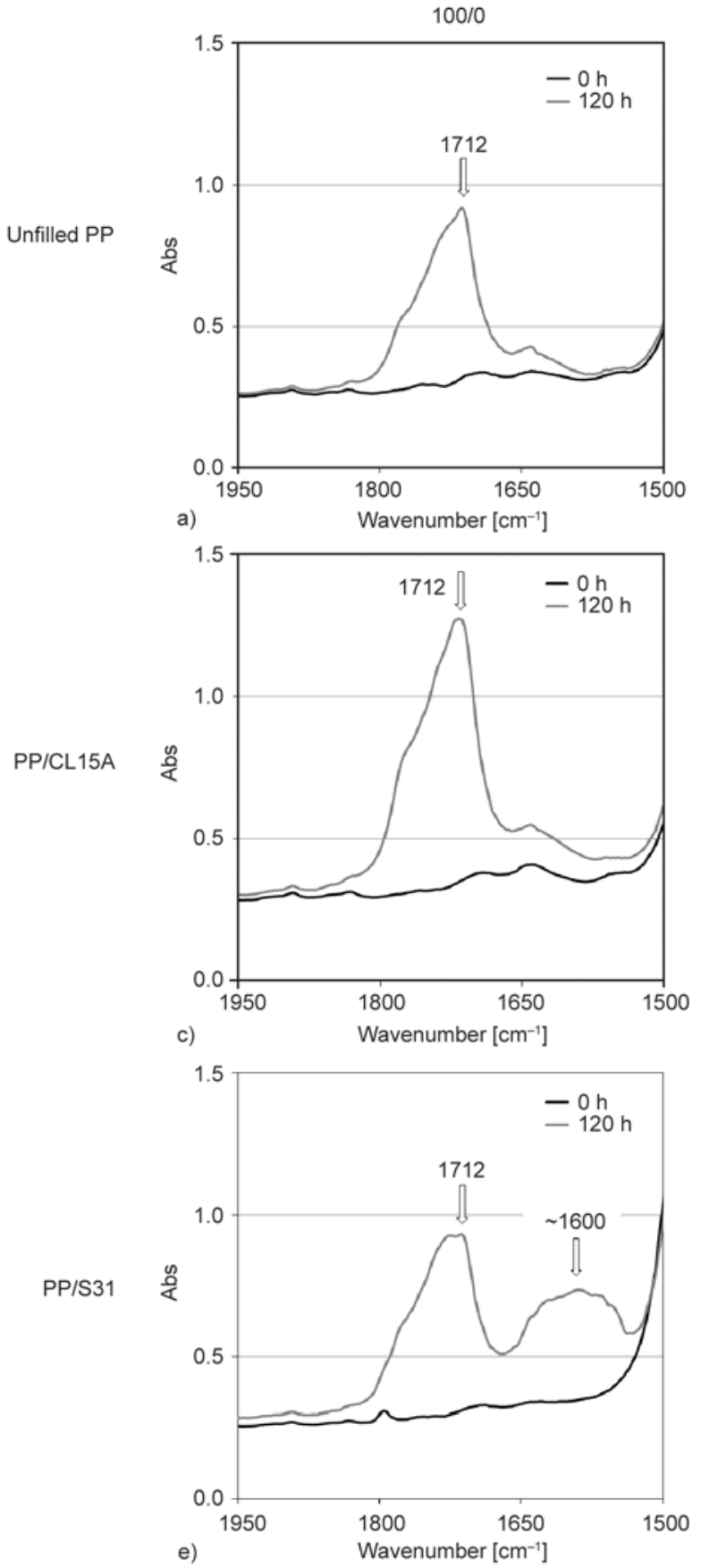

is a striking result, since it suggests that the addition of PPgMA to a PP based nanocomposite, filled with either organomodified clay or precipitated calcium carbonate, can reduce the photo-oxidation rates. As regards the role of the fillers alone (i.e. without taking into account the PPgMA), it can be stated that their presence leads to higher sensitivity to photooxidation, in agreement with our previous studies [19].
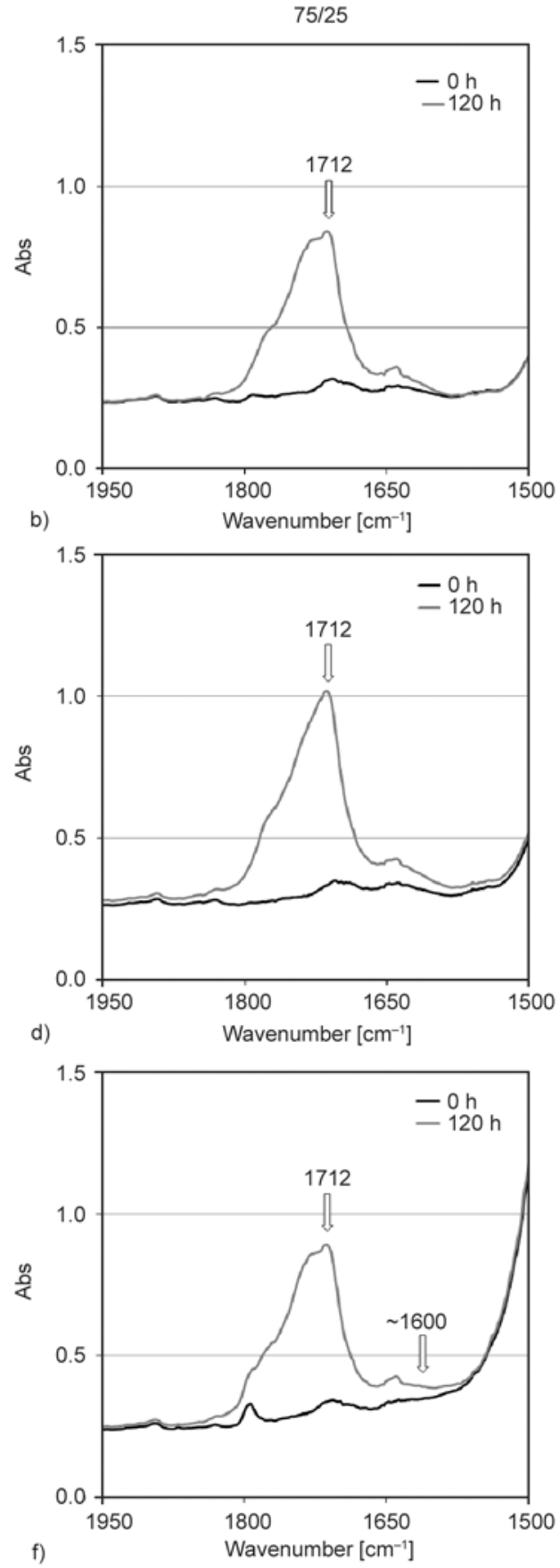

Figure 7. Carbonyl region of FT-IR spectra at $0 \mathrm{~h}$ and $120 \mathrm{~h}$ : (a) PP/PPgMA = 100/0, (b) PP/PPgMA = 75/25, (c) CL15A nanocomposites where PP/PPgMA = 100/0, (d) CL15A nanocomposites where PP/PPgMA = 75/25, (e) S31 nanocomposites where PP/PPgMA $=100 / 0$, (f) S31 nanocomposites where PP/PPgMA $=75 / 25$ 

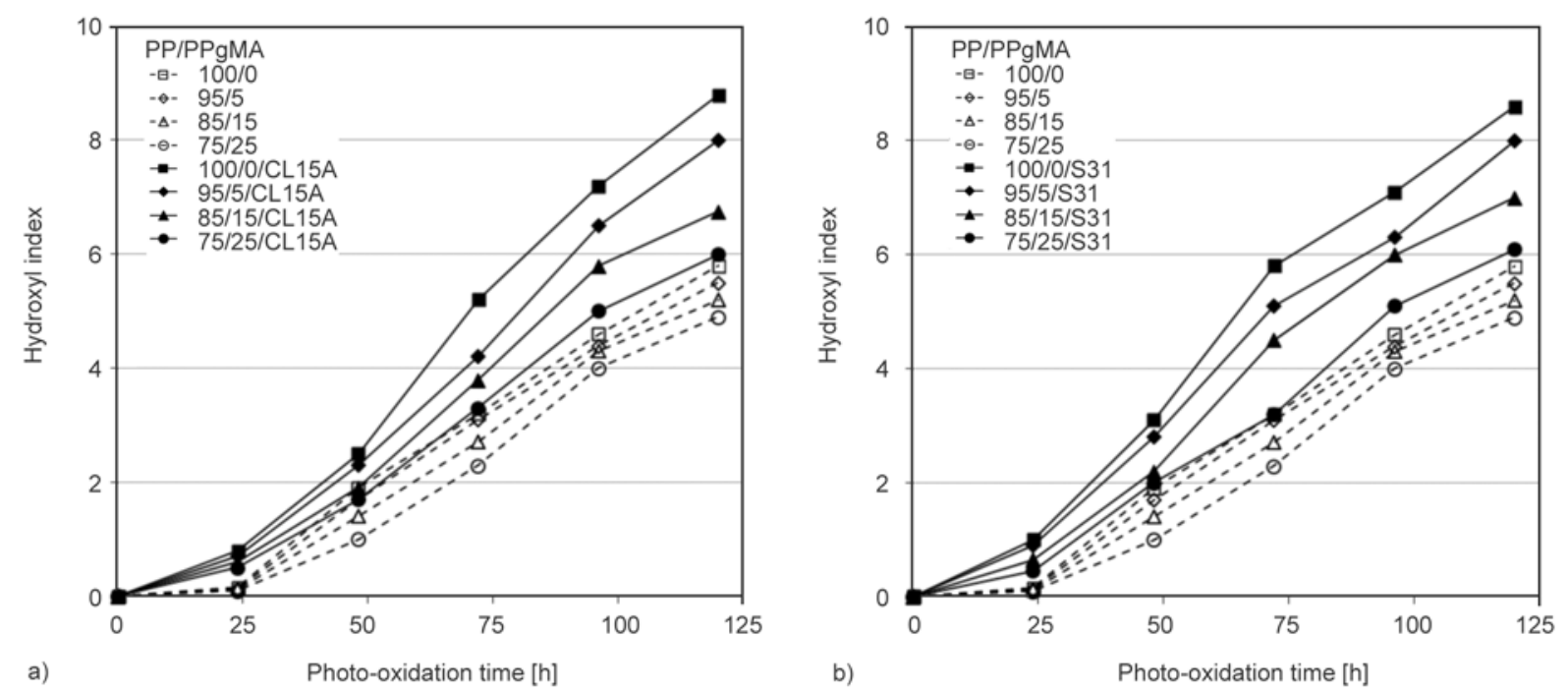

Figure 8. Hydroxyl index of (a) CL15A and (b) S31 nanocomposites at different PP/PPgMA ratios, as a function of the photo-oxidation times

The FT-IR spectra in the carbonyl region are reported in Figure 7a-7f. The spectra show the formation of a peak centered at $1712 \mathrm{~cm}^{-1}$ in PP, PP/CL15A and $\mathrm{PP} / \mathrm{S} 31$ samples upon increasing the photo-oxidation time up to $120 \mathrm{~h}$; furthermore, a wide band at approx. $1600 \mathrm{~cm}^{-1}$ appears in the PP/S31 sample after $120 \mathrm{~h}$, while it is much less evident in the previous samples. This band is attributable to the formation of carboxylic acid salts during weathering, as a result of the reaction between carboxylic acids coming from the PP degradation, and the basic fillers (S31) used in the nanocomposites [19]. However, the situation is different as far as the systems with 75/25 PP-to-PPgMA ratio are concerned. In the case of the binary blend and the CL15A nanocomposite, the shapes of the peaks are similar to those found in the samples without the compatibilizer. With particular concern to the CL15A nanocomposite, the subtended area is significantly smaller, as already shown by the CI data, suggesting that the presence of PPgMA actually reduces the photo-oxidation products formation in the carbonyl region. This can be explained by considering that the acid sites formed onto the clay platelets during photooxidation (due to the Hoffmann elimination of the organomodifier [17]) are partially hindered by the presence of the maleic anhydride which creates a physical barrier. However, the results are even more interesting when the S31 nanocomposite is taken into account. The spectra clearly show that the band at $1600 \mathrm{~cm}^{-1}$ does not appear, even after $120 \mathrm{~h}$ of accelerated weathering. This suggests that the presence of a high amount of PPgMA hinders the reac- tion between the filler and the degradation products coming from the photo-oxidized PP, and thus the formation of carboxylic acid salts. This is probably due to the PPgMA encapsulating (at least partially, as already described in the discussion on the morphology) the S31 particles and thus slowing down the reactions with the carboxylic acids.

The above considerations regarding the role of PPgMA are proved also by the morphology improvements already investigated by SEM and TEM and discussed before. The complex morphology of both CL15A and S31 filled nanocomposites with 75/25 PP-to-PPgMA ratio is due to two contrasting effects, i.e. the blend formation and the effect of the filler. Finally, Figure 8 and Figure 9a-9f, report respectively the Hydroxyl index (HI) and the FT-IR spectra in the hydroxyl region of the same samples. The results confirm the observations done with regard to the carbonyl region: the presence of PPgMA reduces the formation of photo-oxidation products, increasingly upon increasing the PPgMA content.

\section{Conclusions}

In this work, the effect of the addition of different amounts of PPgMA to PP-based nanocomposites has been investigated. An accurate study on the mechanical behavior, as well as the morphology of the prepared systems before accelerated weathering has been carried out. It was found that the addition of PPgMA leads to a reduction of the elastic modulus of pristine PP, however it can also improve the adhesion between the filler and the polymer matrix, thus leading to improvements of the elastic modu- 

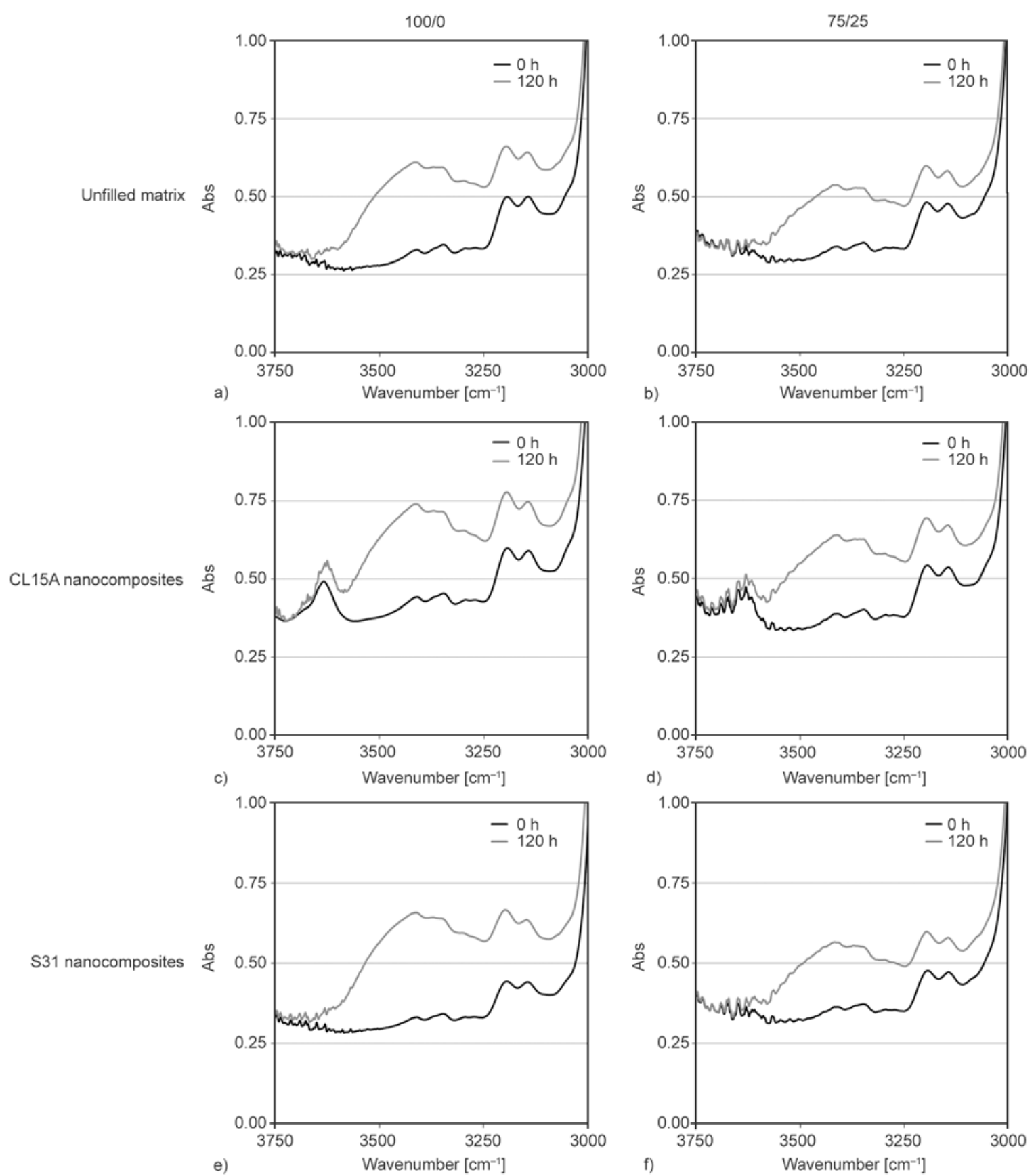

Figure 9. Hydroxyl region of FT-IR spectra at $0 \mathrm{~h}$ and $120 \mathrm{~h}$ : (a) PP/PPgMA = 100/0, (b) PP/PPgMA = 75/25, (c) CL15A nanocomposites where PP/PPgMA = 100/0, (d) CL15A nanocomposites where PP/PPgMA = 75/25, (e) S31 nanocomposites where PP/PPgMA = 100/0, (f) S31 nanocomposites where PP/PPgMA = 75/25

lus. On the other hand, higher amounts of PPgMA can also lead to the formation of heterogeneities which, in turn, affect the tensile strength and the elongation at break. However, the morphology was positively affected by the presence of PPgMA, especially in the case of clay-filled nanocomposites, where the clay morphology turned from predominantly intercalated to predominantly exfoliated.
The photo-oxidation behavior seems to be positively affected by the presence of PPgMA. From the mechanical properties standpoint, most of the systems appeared to have similar behavior starting from about 48 hours accelerated weathering, due to the heterogeneity of the systems; on the other hand, FT-IR analysis revealed that the addition of PPgMA significantly reduced the formation of photo-oxidation products in the nanocomposites; in particular, 
clay nanocomposites showed a reduced formation of photo-oxidation products in the carbonyl region, while calcium carbonate nanocomposites experienced a dramatic reduction in the formation of photo-oxidation products related to carboxylic acid salts, coming from the interaction between the basic filler and the photo-oxidation products from the PP.

\section{Acknowledgements}

This work has been financially supported by University of Palermo RS ex-60\% (ORPA07XR52: 'Comportamento foto-ossidativo di sistemi multi-componenti a base polimerica').

\section{References}

[1] Usuki A., Kojima Y., Kawasumi M., Okada A., Fukushima Y., Kurauchi T.: Synthesis of nylon 6-clay hybrid. Journal of Materials Research, 8, 1179-1184 (1993). DOI: $10.1557 / J M R .1993 .1179$

[2] Jordan J., Jacob K. I., Tannenbaum R., Sharaf M. A., Jasiuk I.: Experimental trends in polymer nanocomposites - A review. Materials Science and Engineering: A, 393, 1-11 (2005).

DOI: $10.1016 /$ j.msea.2004.09.044

[3] Pfaendner R.: Nanocomposites: Industrial opportunity or challenge? Polymer Degradation and Stability, 95, 369-373 (2010).

DOI: $10.1016 /$ j.polymdegradstab.2009.11.019

[4] Chan C-M., Wu J., Li J-X., Cheung Y-K.: Polypropylene/calcium carbonate nanocomposites. Polymer, 43, 2981-2992 (2002).

DOI: $10.1016 / \mathrm{S} 0032-3861(02) 00120-9$

[5] Lam T. D., Hoang T. V., Quang D. T., Kim J. S.: Effect of nanosized and surface-modified precipitated calcium carbonate on properties of $\mathrm{CaCO}_{3}$ /polypropylene nanocomposites. Materials Science and Engineering A, 501, 87-93 (2009).

DOI: $10.1016 / \mathrm{j} . \mathrm{msea} .2008 .09 .060$

[6] Salvetat-Delmotte J. P., Rubio A.: Mechanical properties of carbon nanotubes: A fiber digest for beginners. Carbon, 40, 1729-1734 (2002).

DOI: 10.1016/S0008-6223(02)00012-X

[7] Coleman J. N., Khan U., Blau W. J., Gun'ko Y. K.: Small but strong: A review of the mechanical properties of carbon nanotube-polymer composites. Carbon, 44, 1624-1652 (2006).

DOI: $10.1016 /$ j.carbon.2006.02.038

[8] Filippi S., Dintcheva N. Tz., Scaffaro R., La Mantia F. P., Polacco G., Magagnini P.: Effects of organoclay on morphology and properties of nanocomposites based on LDPE/PA-6 blends without and with SEBS-g-MA compatibilizer. Polymer Engineering and Science, 49, 1187-1197 (2009).

DOI: $10.1002 /$ pen.21361
[9] La Mantia F. P., Dintcheva N. Tz., Malatesta V., Pagani F.: Improvement of photo-stability of LLDPEbased nanocomposites. Polymer Degradation and Stability, 91, 3208-3213 (2006).

DOI: $10.1016 /$ j.polymdegradstab.2006.07.014

[10] Shah R. K., Paul D. R.: Organoclay degradation in melt processed polyethylene nanocomposites. Polymer, 47, 4075-4084 (2006).

DOI: $10.1016 /$ j.polymer.2006.02.031

[11] Morlat-Therias S., Fanton E., Gardette J. L., Dintcheva N. T., La Mantia F. P., Malatesta V.: Photochemical stabilization of linear low-density polyethylene/clay nanocomposites: Towards durable nanocomposites. Polymer Degradation and Stability, 93, 1776-1780 (2008). DOI: 10.1016/j.polymdegradstab.2008.07.031

[12] Qin H., Zhao C., Zhang Z., Chen G., Yang M.: Photooxidative degradation of polyethylene/montmorillonite nanocomposite. Polymer Degradation and Stability, 81, 497-500 (2003). DOI: $10.1016 / \mathrm{S} 0141-3910(03) 00136-8$

[13] Mailhot B., Morlat S., Gardette J-L., Boucard S., Duchet J., Gérard J-F.: Photodegradation of polypropylene nanocomposites. Polymer Degradation and Stability, 82, 163-167 (2003). DOI: $10.1016 / \mathrm{S} 0141-3910(03) 00179-4$

[14] Botta L., Dintcheva N. Tz., La Mantia F. P.: The role of organoclay and matrix type in photo-oxidation of polyolefin/clay nanocomposite films. Polymer Degradation and Stability, 94, 712-718 (2009). DOI: 10.1016/j.polymdegradstab.2008.12.017

[15] Leroux F., Meddar L., Mailhot B., Morlat-Therias S., Gardette J-L.: Characterization and photooxidative behaviour of nanocomposites formed with polystyrene and LDHs organo-modified by monomer surfactant. Polymer, 46, 3571-3578 (2005).

DOI: $10.1016 /$ j.polymer.2005.03.044

[16] Morlat-Therias S., Mailhot B., Gonzalez D., Gardette J-L.: Photooxidation of polypropylene/montmorillonite nanocomposites. 2. Interactions with antioxidants. Chemistry of Materials, 17, 1072-1078 (2005). DOI: $10.1021 / \mathrm{cm} 0401721$

[17] Dintcheva N. Tz., Al-Malaika S., La Mantia F. P.: Effect of extrusion and photo-oxidation on polyethylene/clay nanocomposites. Polymer Degradation and Stability, 94, 1571-1588 (2009).

DOI: 10.1016/j.polymdegradstab.2009.04.012

[18] Li J., Yang R., Yu J., Liu Y.: Natural photo-aging degradation of polypropylene nanocomposites. Polymer Degradation and Stability, 93, 84-89 (2008). DOI: $10.1016 /$ j.polymdegradstab.2007.10.022

[19] Morreale M., Dintcheva N. T., La Mantia F. P.: The role of filler type in the photo-oxidation behaviour of micro- and nano-filled polypropylene. Polymer International, 60, 1107-1116 (2011) DOI: $10.1002 /$ pi.3049 
[20] La Mantia F. P., Morreale M.: Accelerated weathering of polypropylene/wood flour composites. Polymer Degradation and Stability, 93, 1252-1258 (2008) DOI: $10.1016 /$ j.polymdegradstab.2008.04.006

[21] La Mantia F. P., Morreale M., Scaffaro R., Tulone S.: Rheological and mechanical behavior of LDPE/calcium carbonate nanocomposites and microcomposites. Journal of Applied Polymer Science, 127, 2544-2552 (2013). DOI: 10.1002/app.37875

[22] Krimm S.: Infrared spectra of high polymers. Advances in Polymer Science, 2, 51-172 (1960). DOI: $10.1007 / \mathrm{BFb} 0050351$

[23] Tokihisa M., Yakemoto K., Sakai T., Utracki L. A., Sepehr M., Li J., Simard Y.: Extensional flow mixer for polymer nanocomposites. Polymer Engineering and Science, 46, 1040-1050 (2006). DOI: $10.1002 /$ pen.20542

[24] Harrats C., Thomas S., Groeninckx G.: Micro- and nanostructured multiphjase polymer blend systems. CRC Press, Boca Raton (2006).

[25] Scaffaro R., Morreale M., Mirabella F., La Mantia F. P.: Preparation and recycling of plasticized PLA. Macromolecular Materials and Engineering, 296, 141-150 (2011).

DOI: $10.1002 /$ mame.201000221
[26] García-López D., Gobernado-Mitre I., Merino J. C., Pastor J. M.: Effect of the amount and funtionalization grade of PPgMA compatibilization agent in polypropylene/clay nanocomposites. Polymer Bulletin, 59, 667676 (2007).

DOI: $10.1007 / \mathrm{s} 00289-007-0810-9$

[27] Sahoo S., Ambre A., Jagtap R.: Effect of functionality and melt flow index of maleic anhydride grafted polypropylene on polypropylene clay nanocomposites. Journal of Polymer Materials, 25, 601-612 (2008).

[28] Filippone G., Dintcheva N. Tz., La Mantia F. P., Acierno D.: Using organoclay to promote morphology refinement and co-continuity in high-density polyethylene/polyamide 6 blends - Effect of filler content and polymer matrix composition. Polymer, 51, 3956-3965 (2010).

DOI: $10.1016 /$ j.polymer.2010.06.044

[29] Filippone G., Dintcheva N. Tz., La Mantia F. P., Acierno D.: Selective localization of organoclay and effects on the morphology and mechanical properties of LDPE/PA11 blends with distributed and co-continuous morphology. Journal of Polymer Science Part B: Polymer Physics, 48, 600-609 (2010).

DOI: $10.1002 /$ polb. 21928 